Check for updates

Cite this: Chem. Sci., 2017, 8, 6645

Accepted 20th July 2017

DOI: $10.1039 / \mathrm{c} 7 \mathrm{sc} 02809 a$

rsc.li/chemical-science

\section{Catalytic asymmetric hydroxylative dearomatization of 2-naphthols: synthesis of lacinilene derivatives $\uparrow$}

\author{
Yu Zhang, (D) Yuting Liao, (D) Xiaohua Liu, (D) * Xi Xu, Lili Lin (D) and Xiaoming Feng (D) * \\ An enantioselective hydroxylative dearomatization of 2-naphthols with oxaziridines has been accomplished \\ using a $N, N^{\prime}$-dioxide-scandium(III) complex catalyst. Various substituted ortho-quinols could be obtained in \\ high yields (up to 99\%) and enantioselectivities (up to 95 : 5 er). This methodology could be applied in the \\ synthesis of bioactive lacinilenes in a gram-scale reaction. Based on the experimental investigations and \\ previous work, a possible catalytic model was proposed.
}

\section{Introduction}

Substituted ortho-quinols are essential structural motifs in a number of natural products and pharmaceuticals. ${ }^{1}$ For instance, chiral lacinilene derivatives (Fig. 1), a series of phytoalexines isolated from cotton plants, have been utilized for inhibiting the growth of cotton bacterial pathogens, such as Xanthomonas campestris or malvacearum..$^{2}$ Studies have showed that the $(S)$-enantiomer of lacinilene $\mathrm{C}$ is more active than the $(R)$-enantiomer. ${ }^{2 c}$ While these biological activities provide a justification for the development of approaches to the synthesis of enantiomerically enriched lacinilene derivatives, novel catalytic enantioselective methods remain limited..$^{2 b, d}$

Optically active lacinilene derivatives in nature were proposed to be produced enzymically from the oxidation of dihydroxycadalenes, thus it is of practical interest to discover a catalytic asymmetric oxidative dearomatization route to the synthesis of these cadinanes. ${ }^{3}$ Compared with other successful dearomatization events of phenols or naphthols, ${ }^{4,5}$ controlling the chemo-, regio- and enantioselectivity of the asymmetric

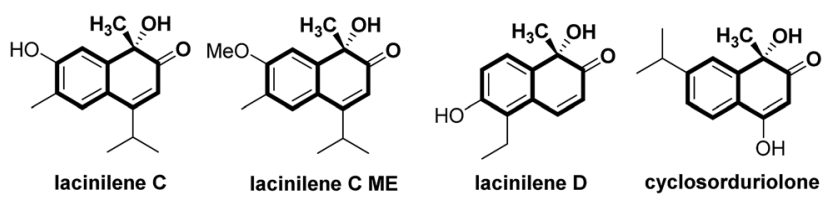

Fig. 1 Representative active lacinilene derivatives bearing ortho-quinol structures.

Key Laboratory of Green Chemistry \& Technology, Ministry of Education, College of Chemistry, Sichuan University, Chengdu 610064, China. E-mail: liuxh@scu.edu.cn; xmfeng@scu.edu.cn; Fax: +86 28 85418249; Tel: +86 2885418249

$\dagger$ Electronic supplementary information (ESI) available. CCDC 1536822. For ESI and crystallographic data in CIF or other electronic format see DOI: 10.1039/c7sc02809a hydroxylative dearomatization is more difficult, ${ }^{6}$ as there might be serious side reactions in the presence of oxidants including overoxidation of alkene functions, competitive para-oxidation and homocoupling. ${ }^{6 c, e}$ Additionally, the ortho-quinol product could undergo an unexpected $\alpha$-ketol rearrangement, which enhances the difficulty of controlling the reactivity and selectivity. ${ }^{6 a, 7}$ In this respect, only a few reports related to asymmetric hydroxylative dearomatization of phenols or naphthols have been reported. Asymmetric oxidative dearomatization of phenolate mediated by copper-sparteine-dioxygen complexes followed a $[4+2]$ dimerization cascade, giving bicyclo[2.2.2] octenones as the final products. ${ }^{6 a}$ Several chiral hypervalent organoiodine compounds were developed for the asymmetric hydroxylative dearomatization of phenols and 1-naphthols. ${ }^{6 b-e}$ Taking these examples into account, we want to engage in discovering new enantioselective strategies for the synthesis of ortho-quinol moieties with improved efficiency and selectivity. Here, we present an efficient asymmetric hydroxylative dearomatization of 2-naphthols catalyzed by a chiral $N, N^{\prime}$-dioxidescandium(III) complex catalyst. ${ }^{8}$ The process could be applied to the synthesis of various 1-hydroxy-1-alkyl-naphthalen-2-one derivatives including lacinilene $\mathrm{C}$ methyl ether and lacinilene $\mathrm{D}$, in high to excellent yields and good enantioselectivities under mild reaction conditions (Scheme 1).

\section{Results and discussion}

We selected the hydroxylative dearomatization of 1-methylnaphthalen-2-ol 1a as the model substrate using 3-phenyl-2tosyl-1,2-oxaziridine $2 \mathrm{a}$ as the oxidant which was proven to be chemoselective as a phase-transfer-catalyst under basic conditions (Table 1) $\cdot{ }^{7 a}$ Initially, the catalytic asymmetric reaction was performed with $10 \mathrm{~mol} \%$ of chiral $N, N^{\prime}$-dioxide $\mathbf{L}-\mathbf{P i P r}_{2}-\mathrm{Sc}(\mathrm{OTf})_{3}$ complex in DCM at $30^{\circ} \mathrm{C}$, and the desired product 3a could be obtained dominantly with $80: 20$ er while the $\alpha$-ketol rearrangement byproduct $4 \mathbf{a}$ was isolated in around one-fourth of 
Previous work: Asymmetric hydroxylative dearomatization of phenols and 1-naphthols<smiles>[R]c1ccc2ccccc2c1O</smiles>

Cat*:

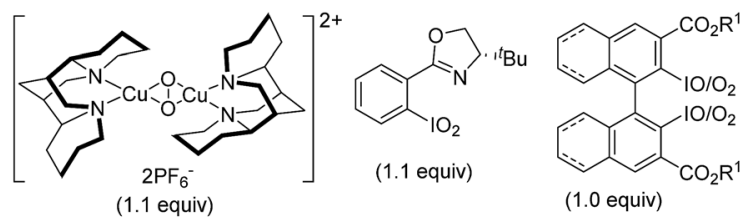

(1.1 equiv)

(1.0 equiv)

This work: Asymmetric hydroxylative dearomatization of 2-naphthols

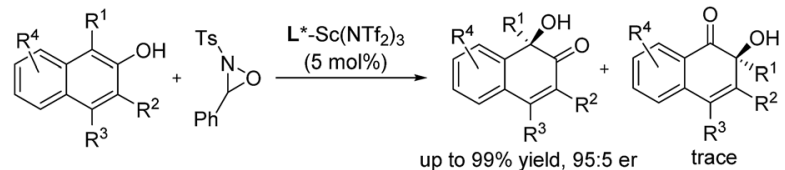

- A straightfoward asymmetric access to lacinilene motifs - High oxidation efficiency and good enantioselectivities

- Low catalyst loading and gram-scale synthesis

Scheme 1 Catalytic asymmetric hydroxylative dearomatization of phenols and naphthols.

Table 1 Optimization of the reaction conditions ${ }^{a}$<smiles>Cc1cccc2ccccc12</smiles><smiles>[Al]=NOc1ccccc1</smiles>

$( \pm)-2 a$

1a

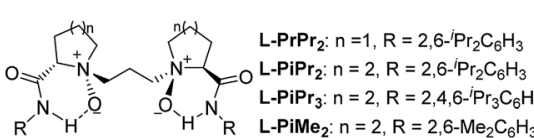

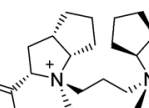

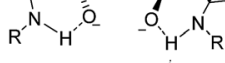

$L-\operatorname{RaPr}_{2}: \mathrm{R}=2,6-\mathrm{Pr}_{2} \mathrm{C}_{6} \mathrm{H}_{3}$

\begin{tabular}{|c|c|c|c|c|c|}
\hline Entry & Metal salt & $\mathbf{L}^{*}$ & Yield $^{b}(\%)$ & Ratio $(3 \mathbf{a} / 4 \mathbf{a})^{c}$ & $\operatorname{er}(3 \mathbf{a})^{c}$ \\
\hline 1 & $\mathrm{Sc}(\mathrm{OTf})_{3}$ & $\mathrm{~L}-\mathbf{P i P r}_{2}$ & 96 & $73: 27$ & $80: 20$ \\
\hline 2 & $\mathrm{Sc}(\mathrm{OTf})_{3}$ & $\mathrm{~L}-\mathrm{PrPr}_{2}$ & 99 & $79: 21$ & $63: 37$ \\
\hline 3 & $\mathrm{Sc}(\mathrm{OTf})_{3}$ & $\mathbf{L}-\mathbf{R a P r}_{2}$ & 99 & $75: 25$ & $53.5: 46.5$ \\
\hline 4 & $\mathrm{Sc}(\mathrm{OTf})_{3}$ & L-PiMe 2 & 90 & $>95: 5$ & $60: 40$ \\
\hline 5 & $\mathrm{Sc}(\mathrm{OTf})_{3}$ & L-PiPr 3 & 96 & $89: 11$ & $73: 27$ \\
\hline 6 & $\mathrm{Sc}\left(\mathrm{NTf}_{2}\right)_{3}$ & L-PiPr 2 & 99 & $>95: 5$ & $92: 8$ \\
\hline $7^{d}$ & $\mathrm{Sc}\left(\mathrm{NTf}_{2}\right)_{3}$ & $\mathbf{L}-\mathbf{P i P r}_{2}$ & 99 & $>95: 5$ & $95: 5$ \\
\hline $8^{e}$ & $\mathrm{Sc}\left(\mathrm{NTf}_{2}\right)_{3}$ & $\mathrm{~L}-\mathrm{PiPr}_{2}$ & 86 & $>95: 5$ & $93.5: 6.5$ \\
\hline $9^{d, f}$ & $\mathrm{Sc}\left(\mathrm{NTf}_{2}\right)_{3}$ & $\mathrm{~L}-\mathrm{PiPr}_{2}$ & 99 & $>95: 5$ & $94.5: 5.5$ \\
\hline
\end{tabular}

${ }^{a}$ Unless otherwise noted, the reactions were performed with $\mathrm{L}^{*} / \mathrm{Sc}(\mathrm{III})$ $(1: 1,10 \mathrm{~mol} \%), 1 \mathrm{a}(0.10 \mathrm{mmol})$ and $2 \mathrm{a}(2.0$ equiv. $)$ in DCM $(1.0 \mathrm{~mL})$ under $\mathrm{N}_{2}$ at $30{ }^{\circ} \mathrm{C}$ for $3 \mathrm{~h}$. ${ }^{b}$ Isolated yield by silica gel chromatography. ${ }^{c}$ Determined by chiral HPLC analysis. ${ }^{d} 5 \mathrm{~mol} \%$ catalyst loading at $0{ }^{\circ} \mathrm{C} .{ }^{e} 1 \mathrm{~mol} \%$ catalyst loading at $0{ }^{\circ} \mathrm{C}$ for 4 h. ${ }^{f} \mathbf{2 a}$ (1.5 equiv.) was used.

a $96 \%$ total yield (Table 1, entry 1). The evaluation of the structure of the $N, N^{\prime}$-dioxides showed that $\mathbf{L}-\mathbf{P i P r}_{2}$ was the optimal ligand in terms of the enantioselectivity albeit ligand $\mathbf{L}-\mathbf{P i M e} \mathbf{C}_{2}$ and $\mathbf{L}-\mathbf{P i P r}_{\mathbf{3}}$ improved the yield of the desired product $\mathbf{3 a}$ (entries 2-5). Fortunately, changing the counterion of the scandium salt from ${ }^{-}$OTf to ${ }^{-} \mathrm{NTf}_{2}$ could suppress the $\alpha$-ketol rearrangement, delivering the quinol 3a in a 99\% yield with
92 : 8 er (Table 1, entry 6). Further optimization of the reaction conditions, such as decreasing the temperature and the catalyst loading to $5 \mathrm{~mol} \%$, resulted in slightly improved enantioselectivity with maintained efficiency (entry 7). Lowering the catalyst loading to $1 \mathrm{~mol} \%$ or the amount of the oxidant 2 a decreased either the yield or the selectivity a little (entries 8 and 9 ). We therefore chose the reaction conditions in Table 1, entry 7 for further studies.

We next explored the substrate scope of 2-naphthols (Table 2). The introduction of bromo or methoxyl groups at the C6-position of 2-naphthols had no obvious effect on the result. The 6-aryl substituted 2-naphthol derivatives 1d-1l tethering various electron-donating and electron-withdrawing substituents could undergo the transformations smoothly, providing the products $3 \mathbf{d}-31$ in $95-99 \%$ yield and $93.5: 6.5-95: 5$ er. It was noteworthy that 6-alkenyl and alkynyl substituted substrates 1m-1q were compatible with the reaction conditions, and no aminohydroxylation of the unsaturated carbon-carbon bond occurred, giving the hydroxylative dearomatization products $\mathbf{3 m - 3 q}$ in good to excellent yields and enantioselectivities. ${ }^{9}$

Table 2 Substrate scope for 2-naphthols ${ }^{a}$

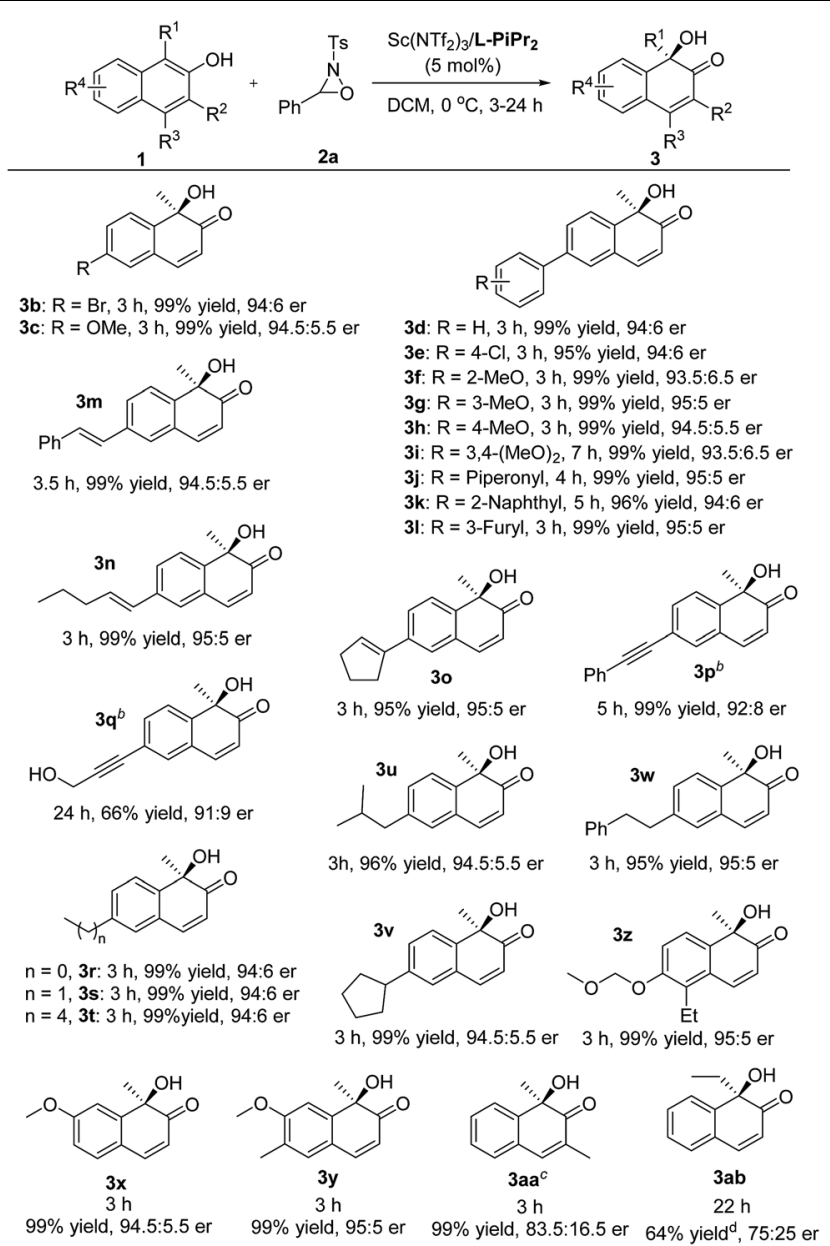

${ }^{a}$ Reaction conditions: the same as entry 7 in Table $1 .{ }^{b} 10 \mathrm{~mol} \%$ catalyst loading. ${ }^{c} \mathrm{~L}_{\mathrm{L}} \mathrm{PiEt} \mathbf{t}_{2}-\mathrm{Sc}(\mathrm{OTf})_{3}(1: 1,5 \mathrm{~mol} \%) .{ }^{d}$ Total yield of $3 \mathbf{a b}$ and $\mathbf{4 a b}$, $\mathbf{3 a b} / \mathbf{4 a b}=87: 13$. 
Additionally, 6-alkyl substituted 2-naphthols 3r-3w bearing methyl, ethyl, and butyl groups were well tolerated, accomplishing the asymmetric hydroxylative reaction with the outcomes of 95-99\% yield and $94: 6-95: 5$ er. The installation of substituents to the 5- and 7-positions did not influence the reaction efficiency $(3 \mathbf{x}-\mathbf{3 z})$. The MOM-protected substrate $\mathbf{1 z}$ could deliver the desired product $\mathbf{3 z}$ with good results without any deprotection process occurring under the reaction conditions. However, the increase of steric hindrance at the orthoposition of 2-naphthol was harmful as a consequence (3aa and $3 \mathbf{a b})$.

To show the synthetic utility of the current catalyst system, asymmetric synthesis of bioactive lacinilenes was carried out (Scheme 2). Initially, the direct deprotection of the product $3 z$ under acidic conditions formed the optically active lacinilene $\mathrm{D}$, but an aromatization side product 1-ethyl-5methylnaphthalene-2,6-diol was obtained. ${ }^{2 \boldsymbol{d}, 10}$ It was anticipated that the TBS protecting group could be easily removed under neutral conditions, which might avoid the occurrence of the aromatization process. As expected, the TBS-substituted 2-naphthol 1ae could be easily synthesized from 9 in 66\% yield after 3 steps, which was further enantioselectively oxidized into the product 3ae in quantitative yield and 95:5 er, even when it was performed at the gram scale. The absolute configuration of 3ae from $\mathbf{L}-\mathbf{P i P r}_{2}-\mathrm{Sc}\left(\mathrm{NTf}_{2}\right)_{3}$ complex catalysis was determined to be $(R)$ by X-ray crystal diffraction analysis. ${ }^{\mathbf{1 1}}$ For the benefit of the further differential biological activity study on

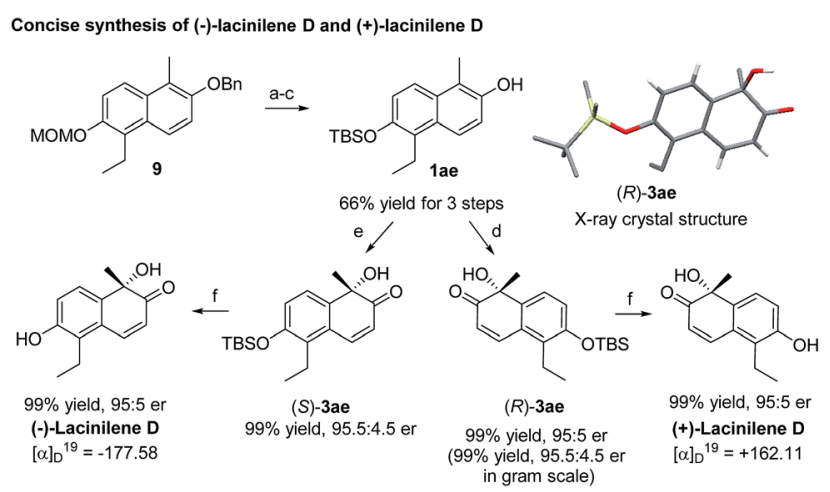

Reaction Condition: a) $\mathrm{HCl}, \mathrm{MeOH}$; b) TBSCl, imidazole, DMF; c) $10 \% \mathrm{Pd} / \mathrm{C}, \mathrm{H}_{2}$ (balloon), EtOH; d) $\mathrm{Sc}(\mathrm{NTf})_{3} / \mathrm{L}-\mathrm{PiPr}_{2}(5 \mathrm{~mol} \%), 2 \mathrm{a}, \mathrm{CH}_{2} \mathrm{Cl}_{2}, 0^{\circ} \mathrm{C}$; e) Sc(NTf) 3 ent-L-PiPr 2 (5 mol\%), $2 \mathrm{a}, \mathrm{CH}_{2} \mathrm{Cl}_{2}, 0^{\circ} \mathrm{C}$ f) TBAF, THF.

Concise synthesis of chiral lacinilene $\mathrm{C}$ methyl ether

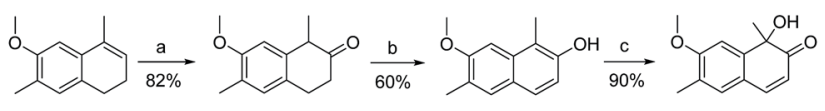
12 13 $1 y$ 3y

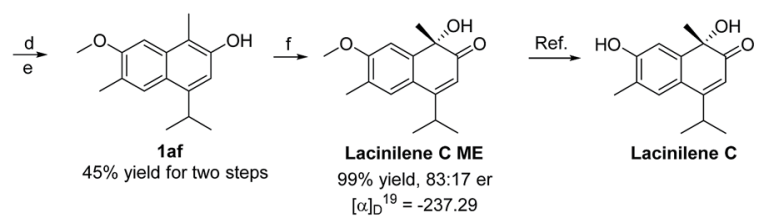

Reaction condition: a) m-CPBA, TsOH $\bullet \mathrm{H}_{2} \mathrm{O}, \mathrm{TFE} / \mathrm{DCM}$; b) $\mathrm{Ce}\left(\mathrm{SO}_{4}\right)_{2} \cdot 4 \mathrm{H}_{2} \mathrm{O}, \mathrm{O}_{2}$ (balloon), ${ }^{\mathrm{t}} \mathrm{BuOH}$; c) $\mathrm{Sc}\left(\mathrm{NTf}_{2}\right)_{3} / \mathrm{rac}-\mathrm{L}-\mathrm{PiPr}_{2}(0.1 \mathrm{~mol} \%), \mathrm{CH}_{2} \mathrm{Cl}_{2}, 35^{\circ} \mathrm{C}$; d) $\mathrm{TMSCl}$, pyridine, $\mathrm{CH}_{2} \mathrm{Cl}_{2} ;$ e) $\mathrm{CuCN}$, iPrMgCl, $\mathrm{BF}_{3} \cdot \mathrm{Et}_{2} \mathrm{O}, \mathrm{THF} / \mathrm{Et}_{2} \mathrm{O}$; f) Sc(OTf) $)_{3} / \mathrm{L}-\mathrm{RaPr}_{2}(5 \mathrm{~mol} \%), \mathrm{CH}_{2} \mathrm{Cl}_{2}, 0^{\circ} \mathrm{C}$.

Scheme 2 Concise synthesis of chiral lacinilene $C$ methyl ether, (-)-lacinilene $\mathrm{D}$ and (+)-lacinilene D. each enantiomer of the chiral lacinilenes, ${ }^{2 c}(S)$-lacinilene D was synthesized using an ent-L-PiPr $-\mathrm{Sc}\left(\mathrm{NTf}_{2}\right)_{3}$ complex with a comparable result of $99 \%$ yield and $95: 5$ er. Next, the synthesis of optically active lacinilene $\mathrm{C}$ methyl ether was explored. The synthetic route began from 1,2-dihydronaphthalene 12, which could be easily accessed from 2-methoxytoluene through a four-step protocol. ${ }^{2 d}$ Subsequent two-step oxidation could afford the 2-naphthol derivative 1y in $49 \%$ yield, which underwent hydroxylative dearomatization catalyzed by $0.1 \mathrm{~mol} \%$ of the $\mathrm{Sc}\left(\mathrm{NTf}_{2}\right)_{3} /$ rac-L-PiPr ${ }_{2}$ complex to produce racemic lacinilene $3 \mathbf{y}$ in $90 \%$ yield. ${ }^{2 d}$ After trimethylsilylation and copper catalyzed 1,4-addition/aromatization, 2 -naphthol 1af could be attained in $45 \%$ yield after two steps. By treatment with oxaziridine $2 \mathbf{a}$ in the presence of Sc(OTf $)_{3} / \mathbf{L}-\mathbf{R a P r}_{2}$, chiral lacinilene $\mathrm{C}$ methyl ether could be obtained in quantitative yield and $83: 17 \mathrm{er}$, which could further transform to lacinilene $\mathrm{C}$ according to the literature. ${ }^{2 b}$

To elucidate the stereochemical course of the oxidation process, some control experiments were conducted (Scheme 3). The optically pure oxaziridine $(S)$-2a reacted with 2-naphthol 1a in the presence of the $\mathrm{Sc}\left(\mathrm{NTf}_{2}\right)_{3} / \mathbf{L}-\mathbf{P i P r} \mathbf{P}_{2}$ complex, affording the $(R)$-quinol 3a in 49\% yield and 95.5: 4.5 er with the recovered oxaziridine $(S)$-2a in $45 \%$ yield. ${ }^{12 d}$ Using ent-L-PiPr ${ }_{2}$ as the ligand, $(S)$-quinol 3a was obtained in 46\% yield and 90 : 10 er with the recovered oxaziridine $(S)-2 \mathrm{a}$ in $52 \%$ yield. This indicates that the chiral matched and mis-matched effect between chiral ligand and chiral oxaziridine was not obvious in this case compared to previous reports, ${ }^{12}$ and there might be negligible interaction between the chiral catalyst and oxaziridine.

To probe into the interaction between the catalysts and 2naphthol, ${ }^{1} \mathrm{H}$ NMR analysis of the mixture of components was carried out (see ESI $\dagger$ for details). The chemical shift of 1-methyl 2-naphthol 1a remained nearly unchanged after $\operatorname{Sc}\left(\mathrm{NTf}_{2}\right)_{3}$ was added. There was an obvious high-field shift for most signals of $\mathbf{1 a}$ after mixing with the $\mathrm{Sc}\left(\mathrm{NTf}_{2}\right)_{3} / \mathbf{L}-\mathbf{P i P r} \mathbf{P}_{2}$ catalyst. This indicates that the chiral catalyst makes the 2-naphthol reactive for hydroxylative reactions. Based on these results and our previous study on the chiral $N, N^{\prime}$-dioxide-metal complex catalysts, ${ }^{\mathbf{8}, 13}$ we suggested an enantioselective catalytic model as shown in Fig. 2. The ligand $\mathbf{L}-\mathbf{P i P r}_{2}$ binds to the scandium(III) center via four oxygens to form a polycyclic octahedral metal complex catalyst. The 2-naphthol coordinates to the metal center at one of the vacant sites, with its $R e$-face shielded by one amide unit of the ligand. Therefore, $2 \mathrm{a}$ preferably attacked the $\alpha$-position of 2-naphthol from the $S i$-face to generate the corresponding $R$-configured product 3ae and imine byproduct. If a substituent was introduced into the $\mathrm{C} 3$ or $\mathrm{C} 4$ positions of 2-naphthol, the steric hindrance discrimination between the two sides of the

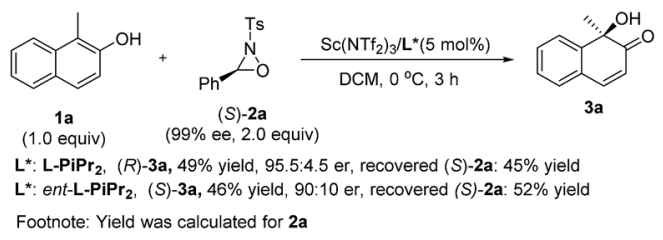

Scheme 3 Control experiments. 


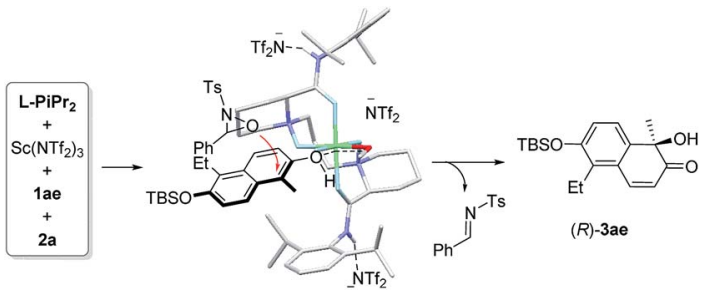

Fig. 2 Proposed enantioselective catalytic model.

hydroxyl group decreases, thus it is difficult to control the faceselection. As a result, the enantioselectivity for the generation of product 3aa and lacinilene $\mathrm{C}$ methyl ether is lower than that for the others.

\section{Conclusions}

In summary, we have described a highly chemo- and enantioselective hydroxylative dearomatization of 2-naphthol derivatives with oxaziridine catalyzed by a chiral $N, N^{\prime}$-dioxide$\mathrm{Sc}\left(\mathrm{NTf}_{2}\right)_{3}$ complex catalyst. The desired substituted ortho-quinols with one quaternary carbon stereogenic center were afforded with high enantioselectivities and reactivity (up to $99 \%$ yield and $95: 5$ er). The $\alpha$-ketol rearrangement byproducts were efficiently suppressed. This new procedure has been successfully applied to the catalytic asymmetric synthesis of the phytoalexines lacinilenes. The application of the $N, N^{\prime}$-dioxide/metal catalyst system in the synthesis of other bioactive molecules will be explored.

\section{Acknowledgements}

The study was funded by the National Natural Science Foundation of China (No. 21290182, 21432006 and 21625205).

\section{Notes and references}

1 (a) D. Magdziak, S. J. Meek and T. R. R. Pettus, Chem. Rev., 2004, 104, 1383; (b) S. P. Roche and J. A. Porco Jr, Angew. Chem., Int. Ed., 2011, 50, 4068.

2 (a) P. W. Jeffs and D. G. Lynn, J. Org. Chem., 1975, 40, 2958; (b) J. P. McCormick, T. Shinmyozu, J. P. Pachlatko, T. R. Schafer and J. W. Gardner, J. Org. Chem., 1984, 49, 34; (c) R. D. Stipanovic, J. P. McCormick, E. O. Schlemper, B. C. Hamper, T. Shinmyozu and W. H. Pirkle, J. Org. Chem., 1986, 51, 2500; (d) K. Krohn and G. Zimmermann, J. Org. Chem., 1998, 63, 4140.

3 For selected examples of asymmetric oxidative dearomatization in the biosynthesis of natural products: (a) A. Bérubé, I. Drutu and J. L. Wood, Org. Lett., 2006, 8, 5421; (b) L. H. Mejorado and T. R. R. Pettus, J. Am. Chem. Soc., 2006, 128, 15625; (c) S. P. Cook, A. Polara and S. J. Danishefsky, J. Am. Chem. Soc., 2006, 128, 16440; (d) J. Gagnepain, F. Castet and S. Quideau, Angew. Chem., Int. Ed., 2007, 46, 1533; (e) A. Rudolph, P. H. Bos, A. Meetsma,
A. J. Minnaard and B. L. Feringa, Angew. Chem., Int. Ed., 2011, 50, 5834.

4 For selected reviews on dearomatization reactions of phenols and naphthols: (a) C.-X. Zhuo, C. Zheng and S.-L. You, Acc. Chem. Res., 2014, 47, 2558; (b) W.-T. Wu, L. Zhang and S.-L. You, Chem. Soc. Rev., 2016, 45, 1570; (c) W. Sun, G. Li, L. Hong and R. Wang, Org. Biomol. Chem., 2016, 14, 2164. For selected recent examples, see: $(d)$ Q. Yin, S.-G. Wang, X.-W. Liang, D.-W. Gao, J. Zheng and S.-L. You, Chem. Sci., 2015, 6, 4179; (e) S.-G. Wang, Q. Yin, C.-X. Zhuo and S.-L. You, Angew. Chem., Int. Ed., 2015, 54, 647; $(f)$ D. Yang, L. Wang, F. Han, D. Li, D. Zhao and R. Wang, Angew. Chem., Int. Ed., 2015, 54, 2185; (g) J. Nan, J. Liu, H. Zheng, Z. Zuo, L. Hou, H. Hu, Y. Wang and X. Luan, Angew. Chem., Int. Ed., 2015, 54, 2356; (h) D. Yang, L. Wang, M. Kai, D. Li, X. Yao and R. Wang, Angew. Chem., Int. Ed., 2015, 54, 9523; (i) S.-G. Wang, X.-J. Liu, Q.-C. Zhao, C. Zheng, S.-B. Wang and S.-L. You, Angew. Chem., Int. Ed., 2015, 54, 14929; (j) L. Yang, H. Zheng, L. Luo, J. Nan, J. Liu, Y. Wang and X. Luan, J. Am. Chem. Soc., 2015, 137, 4876; ( $k$ ) J. Zheng, S.-B. Wang, C. Zheng and S.-L. You, J. Am. Chem. Soc., 2015, 137, 4880; (l) Q. Cheng, Y. Wang and S.-L. You, Angew. Chem., Int. Ed., 2016, 55, 3496; (m) H.-F. Tu, C. Zheng, R.-Q. Xu, X.-J. Liu and S.-L. You, Angew. Chem., Int. Ed., 2017, 56, 3237; (n) D. Shen, Q. Chen, P. Yan, X. Zeng and G. Zhong, Angew. Chem., Int. Ed., 2017, 56, 3242.

5 For selected reviews on recent asymmetric oxidative dearomatization of phenols and naphthols: (a) M. Uyanik and K. Ishihara, Asymmetric Oxidative Dearomatization Reaction, in Asymmetric Dearomatization Reactions, ed. S.-L. You, Wiley-VCH, Weinheim, 2016, ch. 6, pp. 129-152. For examples: (b) T. Dohi, A. Maruyama, N. Takenaga, K. Senami, Y. Minamitsuji, H. Fujioka, S. B. Caemmerer and Y. Kita, Angew. Chem., Int. Ed., 2008, 47, 3787; (c) M. Uyanik, T. Yasui and K. Ishihara, Angew. Chem., Int. Ed., 2010, 49, 2175; (d) M. Uyanik, T. Yasui and K. Ishihara, Tetrahedron, 2010, 66, 5841; (e) T. Oguma and T. Katsuki, J. Am. Chem. Soc., 2012, 134, 20017; (f) T. Dohi, N. Takenaga, T. Nakae, Y. Toyoda, M. Yamasaki, M. Shiro, H. Fujioka, A. Maruyama and Y. Kita, J. Am. Chem. Soc., 2013, 135, 4558; (g) M. Uyanik, T. Yasui and K. Ishihara, Angew. Chem., Int. Ed., 2013, 52, 9215; (h) T. Oguma and T. Katsuki, Chem. Commun., 2014, 50, 5053; (i) S. J. Murray and H. Ibrahim, Chem. Commun., 2015, 51, 2376; (j) D.-Y. Zhang, L. Xu, H. Wu and L.-Z. Gong, Chem.-Eur. J., 2015, 21, 10314; (k) N. Jain, S. Xu and M. A. Ciufolini, Chem.-Eur. J., 2017, 23, 4542.

6 For selected examples of asymmetric hydroxylative dearomatization: (a) S. Dong, J. Zhu and J. A. Porco Jr, J. Am. Chem. Soc., 2008, 130, 2738; (b) J. K. Boppisetti and V. B. Birman, Org. Lett., 2009, 11, 1221; (c) S. Quideau, G. Lyvinec, M. Marguerit, K. Bathany, A. OzanneBeaudenon, T. Buffeteau, D. Cavagnat and A. Chénedé, Angew. Chem., Int. Ed., 2009, 48, 4605; (d) K. A. Volp and A. M. Harned, Chem. Commun., 2013, 49, 3001; (e) C. Bosset, R. Coffinier, P. A. Peixoto, M. El Assal, 
K. Miqueu, J.-M. Sotiropoulos, L. Pouységu and S. Quideau, Angew. Chem., Int. Ed., 2014, 53, 9860.

7 (a) C. Grandclaudon and P. Y. Toullec, Eur. J. Org. Chem., 2016, 260; (b) M. Uyanik, T. Mutsuga and K. Ishihara, Angew. Chem., Int. Ed., 2017, 56, 3956.

8 For reviews on chiral $N, N^{\prime}$-dioxides: $(a)$ X. H. Liu, L. L. Lin and X. M. Feng, Acc. Chem. Res., 2011, 44, 574; (b) X. H. Liu, L. L. Lin and X. M. Feng, Org. Chem. Front., 2014, 1, 298; for recent examples: (c) Q. Yao, Y. T. Liao, L. L. Lin, X. B. Lin, J. Ji, X. H. Liu and X. M. Feng, Angew. Chem., Int. Ed., 2016, 55, 1859; (d) Y. Xia, L. L. Lin, F. Z. Chang, Y. T. Liao, X. H. Liu and X. M. Feng, Angew. Chem., Int. Ed., 2016, 55, 12228; (e) Y. Zhang, Y. T. Liao, X. H. Liu, Q. Yao, Y. H. Zhou, L. L. Lin and X. M. Feng, Chem.-Eur. J., 2016, 22, 15119; (f) Y. T. Liao, X. H. Liu, Y. Zhang, Y. L. Xu, Y. Xia, L. L. Lin and X. M. Feng, Chem. Sci., 2016, 7, 3775.

9 (a) D. J. Michaelis, C. J. Shaffer and T. P. Yoon, J. Am. Chem. Soc., 2007, 129, 1866; (b) D. J. Michaelis, M. A. Ischay and T. P. Yoon, J. Am. Chem. Soc., 2008, 130, 6610.
10 We tested $\mathrm{HCl}, \mathrm{AlCl}_{3} / \mathrm{NaI}, \mathrm{BBr}_{3}$, and $\mathrm{TMSBr}$ to remove the MOM-protecting group, but the corresponding lacinilene D was not observed. The reactions proceeded as follows:

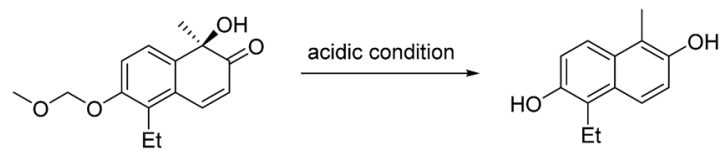

see ref. $2 d$ for details.

11 CCDC 1536822 (3ae) contains the ESI crystallographic data for this paper. $\dagger$

12 (a) P.-L. Shao, X.-Y. Chen and S. Ye, Angew. Chem., Int. Ed., 2010, 49, 8412; (b) S. X. Dong, X. H. Liu, Y. Zhu, P. He, L. L. Lin and X. M. Feng, J. Am. Chem. Soc., 2013, 135, 10026; (c) K. S. Williamson, J. W. Sawicki and T. P. Yoon, Chem. Sci., 2014, 5, 3524; (d) X. B. Lin, S. Ruan, Q. Yao, C. K. Yin, L. L. Lin, X. M. Feng and X. H. Liu, Org. Lett., 2016, 18, 3602.

13 X-ray single-crystal structure of $N, N^{\prime}$-dioxide-Sc(III): Y. L. Liu, D. J. Shang, X. Zhou, X. H. Liu and X. M. Feng, Chem.-Eur. J., 2009, 15, 2055. 